International Review of Research in Open and Distributed Learning Volume 17, Number 3

April - 2016

\title{
Blurring Boundaries in Education: Context and Impact of MOOCs
}

Johan Loeckx

Vrije Universiteit Brussel

\begin{abstract}
The opinions on MOOCs go to extremes, covering a wide variety of topics, affecting economy, pedagogy, and computer science which makes it hard to keep oversight. Despite the many excellent research reports and articles, an overview of the bigger picture, providing a holistic qualitative summary of the different opinions, is still very welcome. Special attention is given to the broader social, cultural, and technological context in which these developments come about. In this paper, it is discussed how the educational industry has received a "wake up call" provoking a global discussion on learning and teaching, accordingly disturbing established boundaries between formal and informal learning, public and forprofit education, teachers and learners and quite intriguingly, between software and teaching practices. Golden opportunities for Artificial Intelligence and Technology Enhanced Learning are unfolding, evidenced by the digitalization movement of education, gamification, and the stringent need for massively scalable (and therefore computerized) personal learning experiences.
\end{abstract}

Keywords: MOOCs, survey, social context, debate, artificial intelligence

\section{Introduction}

The list of learning topics in Massive Open Online Courses (MOOCs) is endless and so are the opinions on MOOCs (Habib \& Woods, 2014). Critics might say that the phenomenon is "Northern American elite universities discovering online courses," a hype created by Silicon Valley entrepreneurs and media stars (Cuban, 2009, p. X). Proponents, on the other hand, predict a global democratization of education and a "reinvention of the university" ("Creative destruction", 214; Friedman, 201). Whatever your stance is, MOOCs are receiving global attention in (a) educational conferences, (b) international press (Pappano, 2012; Friedman, 2013; "Creative destruction", 2014; Borden, 2014; Marcus, 2014a), (c) many blog posts and, last but not least, (d) the many experiments colleges around the globe are setting up. According to moocs.co, a global directory of MOOCS, there were more than 3859 online courses in December 2014, an increase of 300\% in one year's time ("MOOCs Directory", 2014).

\section{Contribution}

Many words have been written in the past few years on MOOCs, making it difficult to see the the forest for the tree. Though excellent articles exist that give an overview of the current state of Cs (Kay, Reimann, Diebold, \& Kummerfeld, 2013; Hollands \& Tirthali, 2014; Yuan \& Powell, 2013), provide a literature 
review (Liyanagunawardena, Adams \& Williams, 2013, Haggard, 2013) or discuss the opportunities for universities (O’Prey, 2013; Sharples et al., 2014; "MIT task force," 2014; Grainger, 2013), the author believes that a summary of the opinions in the running debate would deliver a useful contribution to the field. Furthermore, the major stance in this paper is that the current societal and economical context is crucial to put the different opinions in perspective and to understand and establish the impact and future of MOOCs, especially given the crisis in education that a lot of countries are experiencing. As MOOCs are currently in the centre of the spotlight of what is happening in online distance learning, we will build our discourse from this point of view.

\section{Structure of the Paper}

For this reason, the social, cultural and technological context will be given in which these developments come about. Special attention will be given to how existing boundaries are being dismantled (e.g., between institutions, between formal and informal learning, and public and for-profit education). The debate that has been going for a few years will be summarized in more detail and the potential impact of MOOCs for learners, teachers, governments, institutions, and corporations will be given.

The opinions and information presented in this paper have been gathered from peer reviewed literature as well as grey literature like blogs. The following sources were consulted ${ }^{1}$ : (a) reports by governments and non-governmental organisations on education, distance, and online learning and MOOCs (O'Prey, 2013; $\mathrm{KVAB}$, 2014); (b) articles from peer-reviewed journals including Educause, American Journal of Distance Education, International Review of Research in Open and Distributed Learning (IRRODL), Journal of Research on Technology in Education, and The International Journal of Artificial Intelligence in Education; (c) general books on education, distance learning and pedagogy (such as Moore \& Kearsore, 1; Hattie, 2013; Tokoro \& Steels, 2003; Haber, 2014c); (d) proceedings from conferences like the International Conference on Distance Learning and Education (ICDLE)nd the European MOOCs Stakeholders Summit (EMOOCs) and many others; (e) reports from open universities and consultancy agencies like Gartner; (f) articles in major newspapers and magazines like The New York Times and The Economist; (g) results from Web crawls based on Google Alerts from January 2014 until December 2015. Of all these sources, references and links were investigated as well.

As one of the main goals of this paper was to map out the wide range of opinions expressed in grey literature, the author could not start from an existing holistic framework and has therefore opted an organic approach to organise the many topics. However, to ensure the survey was as complete as possible, LISTNUM the following frameworks have been used for validation: John Hattie's six factors of influence on student achievement (Hattie, 2013); Kjær Global's key trends 2020 for the societal context ("Global key trends 2020”, 2015) and Gartner's top 10 strategic technology trends (Gartner Identifies the Top 10, 2015).

\section{Socio-Economical Context}


Before delving deeper into the running debate and discussing the impact of MOOCs and online learning in general, we will focus on the socio-economical context and situate the current developments within the wider context of education in our global society. Figure 1 illustrates the four pillars in society that provide the current drive and context in the MOOC movement: technology, culture, society, and economy. Each of them will be discussed in more detail in the following sections.

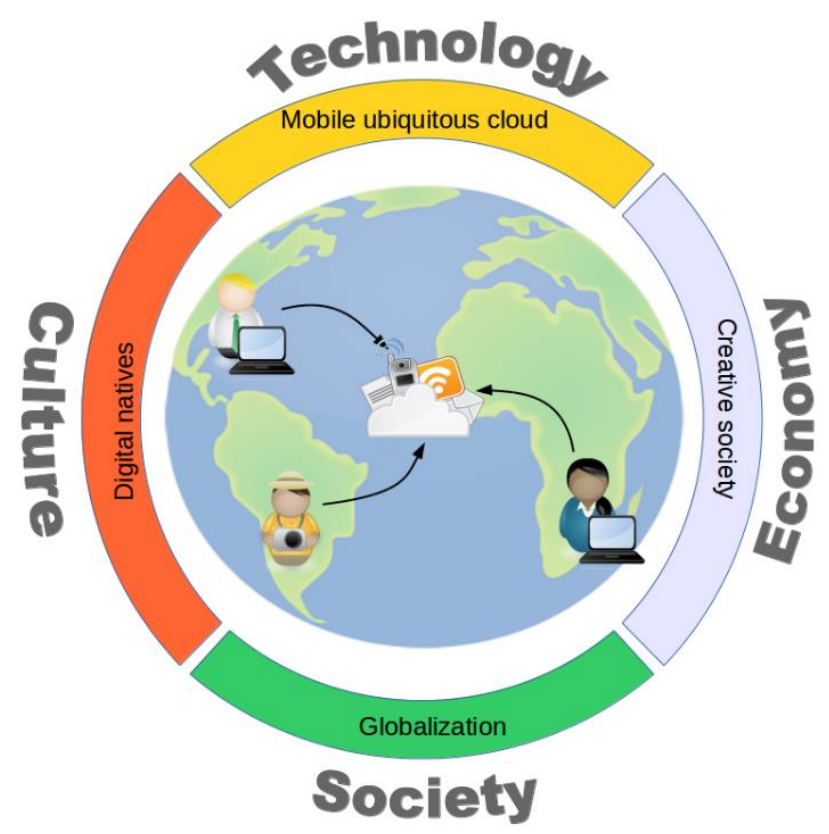

Figure 1. Overview of the context in which MOOCs come about. To fully understand the potential of online distance learning, it is important to take a holistic viewpoint and consider the cultural, economical, technological and social factors that are reshaping education

\section{The Crisis in Education}

As the need for education and life-long learning has never been so high, traditional education comes under increasing pressure (Laurillard, 2002) and even before the coming of MOOCs, it was suggested that education is at an inflection point (Aoun et al., 2013; Carmichael, 2014; Woolf, 2009).

First, there is the issue of democratization. Large numbers of people are still excluded from postsecondary education (Habib \& Woods, 2014), while tuition fees in the West (especially the USA) have risen to such levels that the financial investment seems no longer worth. Moreover, the scale of higher education has expanded considerably without a corresponding increase in means, creating a strain on personalized one-on-one tutoring. Second, in our everyday lives our methods of learning have changed drastically in the last 10 years due to the Internet, mobile phones, social media, email and collaborative platforms like Wikipedia (Davidson \& Goldberg, 2009). Learning institutions have seemed to have evolved far more slowly. Thirdly, the traditional methods we employ, based on a central authority, oneway communication from teacher to student and long attention spans are in deep conflict with the 
environment of our modern society.

This clash has created a crisis in education, with demotivated students, drop-outs, a decrease in knowledge and skill levels as a consequence (Tokoro \& Steels, 2003; Wood, 2014).

\section{A Generation of "Digital Natives" in a Participatory Culture}

Present-day students are technologically immersed and the prevalent role of technology in the life of youngsters has created a new participatory culture amongst the learners of current and coming generations. We are moving away from a world in which some produce and many consume, to a social environment in which everyone has an active stake in the culture that is created (Jenkins, 2009). The current generation of digital natives is very comfortable with technology, and will probably be expecting a greater balance of online and campus-based delivery (Min-sik, 2014). This change in culture, however, is not yet reflected in our educational systems. Jeremy Rifkin stated that "In the traditional industrial classroom, questioning the authority of the teacher is strictly forbidden and sharing information and ideas among students is labelled cheating." (Rifkin, 2014)

\section{A Shift Towards a Creative and Knowledge Society}

The 2000 Organisation for Economic Co-operation and Development (OECD) report "Social Diversity and the Creative Society of the 21st Century" points out that the movement to a knowledge economy or society implies a major dematerialisation of value-added activity and the evolution from homogeneous mass consumption to creative diversity and a decentralisation of responsibility (Stevens, Miller \& Michalski, 2000). So, rather than having workers performing standardized jobs or students following the same curriculum, individual creativity will play a more important role (Creative Destruction, 2014) and lifelong learning will be indispensable.

\section{The Techno-Utopian Age}

From a technological perspective, it is expected that three important forces will reinforce each other and revolutionize the workplaces of the future: social media, omnipresent mobile devices, and cloud computing ("The Nexus of Forces", 2014). Cloud computing has changed the business model of service delivery to an on-demand, pay-for-use model and has severely increased the agility of digital servicesevidenced for example by the explosion of technology start-ups. The mobile revolution, on the other hand, has made all this technology available anywhere at any time (e.g., e-readers). Finally, social imperatives like crowd sourcing and crowd funding has allowed us to construct knowledge that was previously either impossible to create or too expensive to maintain. At the same time, Artificial Intelligence is becoming ever more widespread and considered having high strategic value for businesses and ultimately, educational institutions.

\section{Globalization and Demographic Diversity}

Students in the online realm exhibit quite a different demographic profile than found in a typical college classroom. To start, globalization makes it that students do not necessarily originate from Western countries, are native English speakers, share a common cultural background nor do they have the same gender (Paul, 2014). Second, the ageing of the population and the trend towards life-long learning means 
that the average learner will become older. We can conclude that the heterogeneity of learner communities will only increase in age, gender, cultural background, language, and level of education, while the resistance towards virtual technology will drop.

\section{The Running Debate}

Having discussed the context in which online learning takes place, an extensive overview will now be given of the major debates that are conducted on MOOCs. We will delve deeper into the issue of whether MOOCs will lead to democratization or elitism of education and investigate the claims that MOOCs will mean the end of classical education. Last, the concerns about pedagogies on a massive scale are discussed. Figure 2 summarizes the core of the running debate.

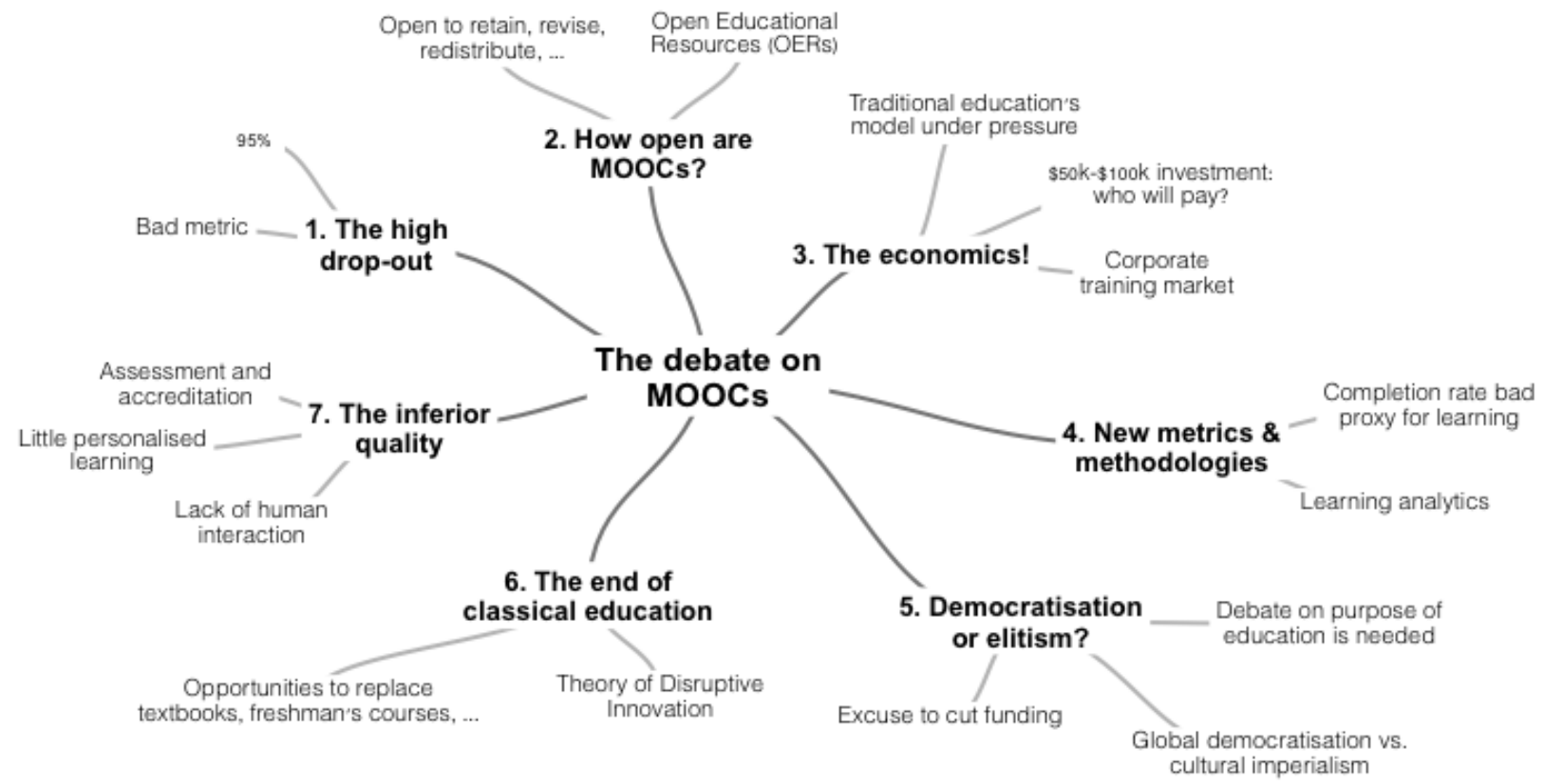

Figure 2. An overview of the running debate on MOOCs in the blogosphere and specialized press. Topics include economical, technical, ped LISTNUM agogical as well as political issues

\section{The High Drop-Out}

Low accomplishment rates are frequently mentioned as a proof that MOOCs are failing (Alcorn, Christensen, \& Emanel, 2014). Yet, more than 80\% of students claim that the MOOC met their objectives, according to surveys filled in after the course. Moreover, research by Harvard and MIT suggests that completion rates are a bad measure for success (Marcus, 2014b): due to the high heterogeneity of the students and wildly varying learning goals, it doesn't make sense to define a "global drop-out" rate (Kizilcec, Piech, \& Schneider, 2013). Online courses can attract students who might otherwise have not been able to attend traditional on-campus instruction because of work, family, or other obligations. This difference in the nature of the student body confounds direct comparison (Allen \& Seaman, 2014). Indisputably, students need more self-discipline during online courses than in regular face-to-face 
courses, without any external schedule enforced (Allen \& Seaman, 2014). The key question is how to find online pedagogies that "scale", in which a large number of students can actively and productively engage (Sharples et al., 2014).

\section{How Open are MOOCs?}

The $\mathrm{O}$ of open in MOOCs is often is equated to "free", meaning that you do not have to pay for a course. Though this was one of the original promises, this model is of course not economically feasible and MOOC providers are experimenting with new business models for education, some in which following a course is no longer free (Dodd, 2014b). More importantly, just because material is free and openly licensed, however, it doesn't mean that access is equal. This interpretation of open as free, differs significantly from what is typically meant with open, namely the free and perpetual permission to engage in the $5 \mathrm{R}$ activities: retain, reuse, revise, remix, and redistribute. The terms of use of Coursera, for example, limit the educational opportunities of MOOCs while really open licensing access (including open credentials, assessments, and competencies) would drastically expand the access around the globe and foster innovation (Wiley, 2014). Initiatives are taken, though, in the context of the open educational resources (OER) movement ("ECO,” n.d.; Brindaalakshmi, 2014; Cannell, 2014).

\section{The Economics}

Traditional education's business model. The traditional business model of education is coming under increasing pressure with rising tuition fees, larger audiences, and higher expectations. For people who cannot afford the tuition fees or do not want to pile up student debt, online variants for a freshman's lecture course definitely make sense. Once these variants on traditional learning will be accepted by employers and students will avoid classical colleges, the financial impact will be huge. Though traditional institutions are currently protected by accreditation and government legislature, this is a situation that probably won't last if democratization is a priority for policy makers.

While universities are typically very open towards sharing content, they are not eager to provide credit for it as this would undermine their business model. In this sense there is an interesting conflict with MOOC platforms, who do not produce the expensive high-quality content themselves, but want to make money charging users for access to this content and according certification. This puts universities in an impasse: because of the substantial investment they have made in MOOCs without credits attached (and thus, no income), they feel the pressure to valorise these online materials anyhow by reusing the courses for credit, accordingly increasing the share of online education in higher education.

The business of accreditation. So, while certification and accreditation currently is a matter restricted mainly to universities, the arrival of MOOCs might well disrupt this situation. For example, specialized interest groups, governments, and foundations are already becoming new (statutory)

authorities for accreditation. One example is the Linux Foundation providing certification for Linux professionals, eagerly sought for by hiring managers (Vaughan-Nichols, 2014). Similarly, the American Council on Education recently decided to create a pool of about hundred courses that will lead to certification. Their main goal is to provide accreditation to the many Americans that have followed higher 
education but do not have degrees (ACE Alternative Credit Project to Increase Attainment Levels for Nontraditional Learners with Some College, No Degee, 2014). This way, they want to serve as an incubator for providing credits and improve the acceptance of these credits by colleges and employers. All institutions with a high reputation on a specific topic will become potential competitors to universities when concerning accreditation.

Zero marginal cost. The whole discussion about economics essentially circles around the issue of zero marginal cost. In an online educational setting, the marginal cost of serving the 100,oooth student is essentially zero (Rifkin, 2014). From this perspective, the discourse is similar to that of cloud computing as the kind of expenditure is different in the old and new model of delivery: developing MOOCs demand a big upfront capital expenditure, but very low operational expenditure, in contrast to traditional teaching (Kim, 2014a).

\section{Metrics and Methodologies Adapted to a Massive Scale}

Current pedagogies are not yet adapted to the massive scale of the Internet. Sensible metrics and analytics can be useful in this context, for learners to serve as an indicator whether they are performing well with respect to their peers, for platforms to tailor the content based upon its background and expertise, or suggest assistance when needed. They are interesting for teachers as well, for example to cluster groups of students based on level, to identify potential problems with the course, and to feed back on their pedagogical effectiveness. For example, completion or certification rates may be easy to count but are a poor proxy for the amount of learning that occurs. Similarly, percentages in general make less sense because of the massive scale: a thousand certificates compared to 200,000 students is a small percentage online, but a huge amount in traditional education!

\section{Democratization or Elitism?}

The utopia. Thomas Friedman from The New York Times declared about MOOCs that "nothing has more potential to lift people out of poverty" (Friedman, 2013) and that lifelong learning for all was a goal that could finally become a reality. A similar voice is heard from tech entrepreneurs (Koller, 2012; $\mathrm{Ng}$ \& Koller, 2012). It is indeed true that MOOCs do not employ entrance criteria prevalent in traditional universities that often filter out students with different cultural background or abilities (Chattopadhyay, 2014). However, truly equal access is more than an easy sign-up procedure, and the access problem people in the developing world experience will not be solved by MOOCs as-is.

The sceptics. At the opposite side, certain people distrust the very reasons behind the whole evolution, pointing out that-as the elite institutions that create the MOOCs do not give credit for themthey treat MOOCs as a philanthropic form of second class education suitable only for the unwashed masses (Bates, 2012). The philosophy department of the San Jose University, has expressed a similar fear in an open letter, stating that the current online (r)evolution will deepen the gap between elite universities (that produce MOOCs) and less wealthy ones, who consume the courses by buying licenses to the providers ("Open Letter to Professor Sandel," 2013). The above reflection that questions the role of elite institutions, echoes fears for the potential danger that they will dominate other universities around the world and could lead to franchising (Goul, 2013; Moe, 2014). There is a lot of scepticism from educational institutions too, fearing "that it's an excuse for state legislatures to cut funding to state universities" 
(Parry, 2013) and thus will lead to elitism. To them, it looks like MOOCs seem like the perfect excuse for not pushing through the reforms so heavily needed to provide affordable and democratic education (Petriglieri, 2013a).

\section{The End of Classical Education}

Role of education. Overall, the common vision in MOOCs on education is economic and a broader debate on the very role of education is missing. MOOC evangelists focus primarily on professional development (Chafkin, 2013) and view education purely as a catalyst for the economy; its ultimate goal is to create workers that fit the needs of corporations. This view is exemplified by Sebastian Thrun: "At the end of the day, the true value proposition of education is employment," (Chafkin, 2013). Certainly, one of its roles is to create skilled workers, but it is definitely not the only role (Petriglieri, 2013a). To develop individuals and cultures is equally important (Petriglieri, 2013), even more so in times of globalization.

In this context, education has been claimed before to be a means of cultural imperialism or colonialism (Carnoy, 1974; Foucault, 1980; Petriglieri, 2013b). The Chinese Government, for example, calls MOOCs "a new mode of cultural transmission ... a new project for us to learn to utilize MOOC in popularizing Chinese culture and strengthening China's soft power." (Hanban, 2014).

The theory of disruptive innovation. One of the frameworks to describe the current developments is the theory of disruptive innovation (Christensen, 2013), a term to describe innovations that create a new market with opportunities that the existing market does not expect. The disruption often occurs by first attracting a different set of customers in a new market and then later penetrating the existing market. Notably this last element is quite recognizable in the context of MOOCs and education.

In this scenario, the mobility of students in MOOCs will increase substantially, potentially leading to the following situati:

- global communities of learners, in which higher ed institutions get access to students they could not reach before and students having access to niche expertise courses;

- a global communities of teachers, not only professionals, but also experts in a field, alumni, and amateurs who can be called upon to assist in tutoring and assessment;

- a global repository of courses and learning modules and material, whether open or in a particular licensing model (Morris, 2014).

As the competition will be quality-driven, this evolution would then lead to polarisation in which a few elite institutions provide courses and the others license their content, with celebrity teachers, not unlike in the movie industry (Pappano, 2012).

Consultancy firm Gartner believes that the evolutions described above will eventually lead to an exostructure as the increased mobility of students, courses, and professors creates the need for services and tools to integrate (Lowendahl, 2014). An open interoperability space at this massive scale requires an 
automated information exchange and a service-oriented architecture in which all the actors in the ecosystem can cooperate and data can flow freely. One of the signs of this evolution are the emergence of micro-credentials that reflect the skills acquired by an individual, whether earned in a university or in the workplace. Increasingly we see organizations basing hiring decisions on proficiency as opposed to hiring for degrees. Governments can play a role in facilitating this exchange.

Potential new markets. It is exemplary for the theory of disruptive innovation that the existing market does not recognize the value of these low-quality courses and therefore ignores its potential. First signs of new markets being exploited are thus found in countries where degrees are lower quality, little respected, or not matched with demand from industry, for example, because traditional education institutes are too slow to respond (Salem, 2014). Second, corporations equally see an opportunity for recruitment of employees with the necessary qualifications, as they are not interested in degrees per se, but in the skills themselves. Also, some jobs need highly qualified workers for which degrees do not exist. In this scenario, institutions could evolve from admission models towards membership models ("MIT Task Force," 2014). A third catalyst is that the younger generation prefers online platforms which are interactive, flexible, and cheap.

\section{Concerns about Quality}

A lot of critical voices are heard from professors in universities and colleges, afraid that inexpensive MOOCs with underperforming pedagogical foundations will replace faculties, warning for the misleading promise of MOOCs that they will improve education (Moe, 2014). Exactly the opposite reasoning is heard too, however, that MOOCs may as well improve the quality of courses globally, as locally organized courses can no longer afford to be of a lower standard than an online course (Allen \& Seaman, 2014). A studyin the US found that about three quarters of the academic leaders considered the learning outcomes in online education on the same or superior level as face-to-face instruction (Allen \& Seaman, 2013). There is, however, general consensus that the best traditional college courses (enriched with online material) will remain superior to any online offering. We will now briefly discuss the main points of criticisms.

Little personalized learning. The current standardized nature of MOOCs, lacking personalized instructional guidance, make current MOOCs suboptimal platforms. With exception of some highly self-motivated and disciplined students, the lack of supervision and guidance hinders effective learning (Nichols, 2014). Also, current MOOCs do not take into account personal differences in learning goals and ambitions, their background, or the pace of learning. Especially with a diverse audience as in MOOCs, these factors are crucial for succeeding (Baer, 2003). In addition, learning material is typically presented in a linear, transmission model fashion, not effectively exploiting pedagogies and other technologies suited for the online realm.

Lack of human interaction. A study by Harvard in the context of MOOCs, revealed that students "emphasized the continuing importance of in-person discussion sessions" ("Online Evolution," 2014, pp. XX) as contact and dialogue between tutors and students are still considered key to teaching and lead to high levels of student satisfaction (Knox, Bayne, MacLeod, Ross, \& Sinclair, 2012; Westervelt, 2013). This necessity of human tutors make some people fear that MOOCs in the end will not keep up to 
their promise, because maintaining a staff-to-student ratio of roughly 1:25 needed to counsel students, will mean that even MOOCs will not scale. For this reason, Laurillard concludes that "education is not a mass customer industry: it is a personal client industry" (Laurillard, 2014, pp. XX). Optimists, on the other hand, believe that social structures will emerge organically to replace at least part of the needed human mentors (Duneier, 2012).

Scalable and reliable assessment. From the moment that universities are starting to provide certificates of equal value to online courses, the credibility of assessment becomes critical (Button, 2014; "Online Master of Science in Computer Science", 2014). There are still some compelling challenges like cheating and scaling to overcome (Webley, 2012). Research into peer and self-assessment look promising and seems to work well when the students level is homogeneous, when students have a similar model of perception of quality and if they are properly trained in grading. Furthermore, evidence seem to indicate that students learn from these kinds of grading (Sadler \& Good, 2006). Still, assessments are in an early stage of development, testing for skills only superficially and not yet in a trustworthy way.

\section{The Impact of MOOCS}

Having discussed the context and global debate, we can now focus on the role that MOOCs are currently playing. Though many colleges and universities (53\%) are still undecided on the impact (Allen \& Seaman, 2014), we can safely say that online learning has become a strategic priority, shifted from research to policy making and is already changing the global education landscape and could continue to do so in the future. Still, there is quite some discrepancy in the opinions of the different stakeholders on the longlasting impact of Massive Open Online Courses for higher education institutions.

Universities themselves are currently rather realistic in their expectations and concentrate mainly on the second-order effects of MOOCs, like improving the visibility of their institution, recruiting students, researching novel pedagogical approaches, or to augment learning (e.g., to replace handbooks; Allen \& Seaman, 2014). Professors and specialists in online learning experiments like the open university movement, are commonly very careful when talking about the impact (Bates, 2012; Knox et al., 2012; Ben-Naim, 2014). Indeed, pedagogical studies show that the impact of computer-assisted instruction (CAI) hasn't kept up with its promises, and its effectiveness has not increased significantly over time (Hattie, 2013).

However, it seems that MOOCs have created a new momentum for online and distance learning. Figure 3 summarizes how MOOCs are already changing the global landscape of education for different stake holders. In the next sections we will discuss the impact, centred on four themes:

- the wake-up call for the educational industry;

- a changing role for teachers;

- a global market of courses; 
- the emerging discipline of online and digital course design.

\section{A Wake-Up Call for Education}

A global discussion on the future of learning. There are some compelling differences with similar moments when Information Technology was believed to revolutionize education. Discussions about the future of education are no longer held in specialized academic circles only, but have extended to blogs and international popular press, between all different stakeholders (teachers, students, colleges, policy makers, investors, etc.). A second difference is the extensive scale of experiments that are being set up globally, sometimes referred to as the MOOC tsunami (Brooks, 2012). Facilitated through the Internet, the shortcomings of online learning are continuously being researched and addressed through active experimentation (Haber, 2014b). According to Martin, the founder of Future Learn, the Internet has opened Pandora 's Box which allows us to globally share information and data, and transmit ideas faster than ever before (Murray, 2014).

An innovation sandbox for education. The fact that the design of a MOOC takes place primarily or completely online, creates an interesting opportunity for comparison as there is a more or less common ground between experiments. Universities have taken this opportunity to open up the debate on the future of their mission and started experimenting with MOOCs ("MIT Task Force," 2014; "Designing the Future(s)," 2014; Myk \& Rasmus, 2014). The central question is how internet technologies like social media and networks, and cloud computing and mobile devices-having shown its disruptive power several times before-can be an innovative force for education. 


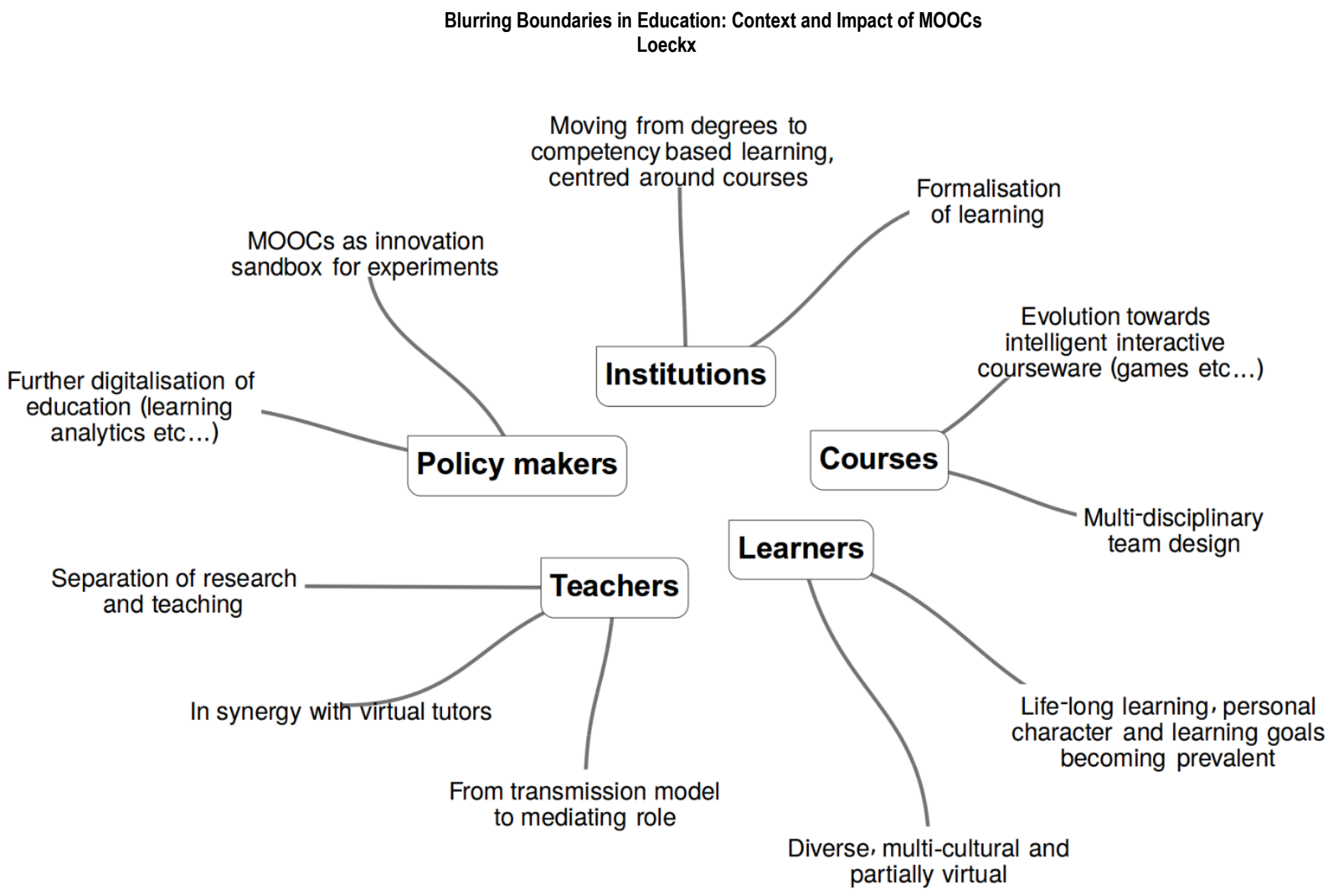

Figure 3. The global landscape of education might significantly change due to digitalization of teaching of which MOOCs are a manifestation. The most remarkable (potential) shifts are summarized for each actor in the ecosystem.

\section{A Changing Role for Teachers}

It is believed that online courses are already changing the role for teachers. They increase the strain on teachers to improve the quality of their teaching, as the teaching of professors at elite institutions become the gold standard (The Opportunities - and Risks -in the MOOC Business Model, 2013; Knox et al., 2012). The value of traditional academic content delivery where there is a valuable online variant, quickly drops to zero, leaving the students expecting more from their institutions than information transmission (Kim, 2014a).

In a way, this evolution makes the professor more valuable as teacher, compared to a pure transmitter of knowledge. Already, competition for academics is observed from individual teaching professionals (corporate trainers), alumni, and field experts, for example on platforms like Udemy (Hepler, 2013).

From a transmission to a mediation model (the flipped classroom or blended learning). A consequence is that the role of teaching in the classroom will probably evolve from "chalk and talk" teaching towards tutoring, where the role of the teacher moves from transmitting knowledge to inspiring and facilitating and mediating discussion, teamwork, and collaboration. In this setting, people's skills become prevalent. Stimulating meta-cognition and self-regulation will therefore become the new 
focal point. Non-cognitive skills (building attitude and character) as well as meta-cognitive strategies (reasoning about learning and what is learnt) will become essential to promote critical thinking and creativity and allow for an active interaction with the material ("Five Habits," 2014). One manifestation of this evolution is the flipped classroom in which lectures are followed at home while problems (harder than typical) are solved in group at the university, assisted and mediated by the professor (Lewis, 2012). It is interesting to note that the underlying pedagogical principles are not novel at all, but known and extensively applied in Montessori, Freinet and similar classrooms for decades (Tokoro \& Steels, 2003). It seems they have finally found their way to the online learning sphere.

Possibly, MOOCs could reinvent the teacher completely, for example introducing the need for more horizontally oriented teachers: tutors that are not proficient in one specific domain, but that can accompany many courses or create a new market for traditional business training centres. This would go hand in hand with the unbundling of teaching and research, as research significantly raises the cost of teaching (Terwiesch \& Ulrich, 2014).

Formalisation of learning. Constructing MOOCs makes professors reflect on their teaching, as they get massive feedback from forums and learn from observing themselves teach (Levander, 2014; Tamburri, 2014). Also the emergence of learning analytics (e.g., A/B testing) allows teachers to get feedback on the effectiveness of their teaching. Knowing what works and what doesn't establishes a process to improve teaching effectiveness (Lapowsky, 2014). Despite vast amounts of educational research, the praxis in the traditional classroom has remained largely based on experience and improvisation.

\section{A Global Market of Courses}

It can be argued that courses are the core atomic learning object in the MOOC ecosystem, leading to micro-credential badges. Rather than centring on degrees, professors, or institutions, MOOCs organize communities of learners and other stakeholders around a specific topic of interest. The concept of learner should thus be understood in its broad meaning of life-long learning, and comprises anyone who is interested in a specific topic, whether they are amateur, graduate student, professional, or professor.

This doesn't mean that online degrees are debarred (like the degree in Georgia University; Georgia Tech, 2014), but rather that the competition and reputation in the far future will potentially arise between courses and professors rather than degrees or institutions. Some courses will be developed over different institutions (Bruff, 2014), or by governments that fund individual MOOC projects to create online courses (Baker, 2014), not unlike research projects.

The global nature of online education allows access to niche areas that may have been hard to attain otherwise. The easy spreading and reuse of course material, however, also introduces the risk that the educational resources won't evolve over time, since the convenience of not having to hire academic personnel to teach, makes it that courses do not co-evolve with the professors who teach them (Bady, 2013). This could lead to an erosion of diversity. However, as the course offer expands, a global competition may well establish a continuous drive for improvement (Bernhard \& Rothberg, 2014). Crowd sourcing of course material could provide a solution to this issue as well. 


\section{Course Experience Design}

Digital born courses. The proper design of courses is even more essential and decisive in online learning than in regular classrooms as there is no teacher to sense the needs of the students and give the necessary feedback. The higher number of students following online courses only adds to the impact of this effect and increasingly, research and MOOCs are popping up on how to create digital courses (Johnson, 2014; Guo, Kim, \& Rubin, 2014; "Monter un MOOC," 2014). Many MOOCs, however, are still the online counterpart of classroom classes (Lipinski, 2014) as teachers are not sufficiently trained and still on the threshold of understanding how to design courses to fully optimize the potential of technology (Abrami et al., 2006). Research has shown that courses that are digitally born are much more effective (Ben-Naim, 2014), but until now, there were little resources or incentives to change this situation. The high drop-out rates, however, have become an important driver to abandon classical, passive, lecture-based learning.

Agile team development of courses. In this light, course experience design (CXD), a term coined by the author, embodies the design of the total virtual learning experience that entails different disciplines and requires different expertise and roles. Current MOOCs are already a mash-up of a variety of fields, including instructional design, user experience design, gamification, virtual tutoring systems, and data mining. This trend is only to continue. In a way, parallels can be drawn with software development projects, facing the same complexities and clashes between the different stake holders and experts. MOOCs also experience the same shift from a single professor creating, delivering, and assessing the effectiveness of a course towards team-based and data-centric activities (Kim, 2014b), engaging instructional designers, media professionals, data scientists (for learning analytics), test designers (for assessment), content experts, game designers, Human-Computer Interfaces (HCI) experts, instructors, researchers, and programmers.

Adaptive learning and intelligent tutoring. Experience with distance education teaches us that it requires "special techniques of course design, special instructional techniques, special methods of communication by electronic and other technology, as well as special organizational and administrative arrangements" (Moore \& Kearsley, 1996, pp. XX). This is not different in online courses and its true power will unravel when human collaborative learning will be combined with adaptive learning and intelligent tutoring systems (ITS). This setting will offer opportunities for learning that are unprecedented: producing explanatory exercises, and providing personalized tutoring, feedback, and exploratory experimentation at a massive scale. Intelligent tutoring systems have already secretly regained popularity (though not referred to with this name), being approached from a user interface design perspective rather than computer science, as was the case in the 1980s and 1990s. Examples are technologies like Smart Sparrow, ExplainEverything!, ALEKS, and MOOCs that incorporate interactive applications, like the course Alien Worlds (Friday, 2014).

\section{Blurring of Boundaries}

The effects above are rather direct and straightforward to observe. On a more abstract level, however, it is expected that the coming of MOOCs will alter well-established boundaries on different aspects of 
education. In a utopian MOOC vision, learning will no longer occur in the context of a fixed degree and at a single university, neither will it occur only at the beginning of someone's career, but throughout its career. Courses will be offered by public as well as for-profit educational institutions, possibly collaborating. Last but not least, the concept of learner and teacher will blur as learning goals and backgrounds start to diverge and teaching will be performed not only by a classical human tutors but also by peer learners and even software. These different aspects of blurring boundaries are discussed in the next sections.

\section{Between Formal and Informal Learning}

With students residing ever more in the digital realm, it will become less clear when and where a course is taking place. Students can follow online courses at their own pace and work anywhere any time, making it fuzzier to define what a classroom is ("MIT task force," 2014). The massive scale with courses having over ten thousand participants, also blurs the personal borders of an individual as the personal bond between teacher and student gradually disappears. The same holds for the concepts of degrees and curricula. In line with life-long learning, in the future, a large part of a person's education will occur during her or his professional career, evolving towards competency-based education (Mazoué, 2014). Already, we observe the trend of companies using MOOCs to keep their employees up-to-date with the latest evolutions (Bersin, 2014; Arizona State University, 2014; Trowsdale \& Marks \& Spencer, 2014).

\section{Between Institutions (Multiversities)}

The walls between educational institutions are fading too. Initiatives like EdCast provide a cloud-based platform that transcends the border of institutions and courses to promote collaboration between universities, governments and corporations. A so-called multiversity allows students to pick a personalized curriculum and according teachers from a variety of institutions ("EdCast," 2014). A more general a trend is observed in which institutions increasingly outsource IT-sensitive and often educationally relevant processes. This practice is called business process outsourcing. We could think of universities outsourcing admissions, grants, funding, student management, and even production of online courses (Lowendahl, 2014).

\section{Between Public and For-Profit Education}

Vice versa, corporations are launching MOOCs in their particular domain of expertise and thus obscure the border between public education and corporate training (Tozzi, 2014; "Online Evolution,", 2014). Recently, discussions start to pop up about the financial independence of public universities, asking whether they should be self-sustaining and possibly even generate revenue.. Incorporating MOOCs in the standard curriculum in order to cut costs is on the agenda ("Public Universities," 2014). A milestone in this respect was "Senate Bill520" in California, USA, that Sebastian Thrun helped draft (Rivard, 2013), requiring California's universities to accept MOOCs from an approved list as course credit. Though the bill has been stalled for now, the potential impact cannot be understated, as it attributes an equal value to MOOCs as to traditional education by forcing it by law (Lewin, 2012).

Besides the fact that the proposal facilitates a direct transfer of public education to for-profit institutions (also monetary), it drastically increases the relative and perceived cost of traditional education. Indeed, to grant the same amount of credits, a purely virtual course is much cheaper than a physical one in which 
you need to pay for infrastructure, supporting personnel, and teachers. Ignoring concerns about quality, why would someone pay for a teacher if the same credential could be obtained from a cheaper online course (Bady, 2013)? Also, the bill would compromise the favourable position that universities as content providers are in, as they would be required to grant credit for courses delivered by outsiders, including for-profit institutions, over which they have no control

\section{Between Teaching Practices and Software}

In a distance learning setting, course material equates to teaching and the way of delivering knowledge and skills overlaps with the course production. In addition, as computer interactivity and modality increases, learning becomes an ever more (inter)active experience and the schism between assessment, learning, and teaching becomes progressively blurred (Haber, 2014a). In this sense, MOOCs have the direct potential to replace textbooks because of their obvious advantages: online courses offer a multimedia interactive experience, with the capability of multi-modal communication. Also, content can be updated any time at no cost (Hamilton, 2014). As courses are delivered through the net, the boundary between course material and interactive, adaptive intelligent tutoring systems are fading as well (Manouselis, Drachsler, Verbert, \& Duval, 2013). Furthermore, MOOCs being intrinsically participatory in design, the strict distinction between teachers and students is disappearing. One extreme is the connectionist MOOCs in which learning material is constructed collaboratively. Besides students helping each other in the forums, courses being created and delivered by students are popping up (Holoiday, 2014). Crowd sourcing initiatives like Wikipedia have shown that these aspirations are not necessarily utopian.

\section{Golden Opportunities for Artificial Intelligence}

One aspect of online learning deserves special attention: the opportunities for artificial intelligence in education. Despite all the promises and expectations, the effects of computer aided instruction and virtual learning environments on learning have been rather disappointing. With exception of carefully crafted intelligent tutoring systems, no significant impact can be observed, which shows-rather painfully-that the advances in technology have not improved the effectiveness of teaching.

One of the main reasons why the huge potential of online courses is not exploited, is the tendency to think in terms of classical course-room lectures. The most interesting experiments have thus emerged by challenging the status quo by loosening the rigid control of learning outcomes and assessment criteria, shifting from content delivery to a learning process, experimenting with alternative assessment methods, games, and so forth (Knox et al., 2012).

The omnipresence and advancement of information technology and the hype for MOOCs seem to have created a new momentum for online learning. Indeed, Web technology has advanced to the stage that complex applications can run in the browser (for example, Office 365), while digital devices and social networks like Facebook have become an integral part of our lives. So, though online learning itself is not new, the current evolutions have brought this form of learning closer to our everyday life, making it more accepted and accessible. 


\section{Digitalization of Education}

Despite the fact that a lot of educators are still not comfortable with technology, a further digitalization of education is observed. Surveys among universities have shown that the importance of online education in their long-term strategy has been increasing slowly but steadily (Allen \& Seaman, 2014). The Chief Information Officer of educational institutions will thus become a more central person for learning, and IT in general of higher strategic importance for the institution (Lowendahl, 2014).

Educational data mining. The emergence of fields like educational data mining (EDM) shows a similar trend ("Educational Data Mining," 2014). EDM aims to apply data mining techniques in order to better understand learning. Its applications range from analysis and visualization of data, providing feedback to instructors and course designers (when do students login, what topics do they visit the most, what patterns can be identified), making recommendations to students (for example of related content to explore), predicting student performance, student modelling, and much more (Romero \& Ventura, 2010). LearnSphere, an online database aimed at collecting information on learning, is another attempt to consolidate the knowledge on learning and unlock its potential to create better online courses (Lynch, 2014a). Similarly, data scientists will have a seat at the table when designing courses, for example to translate learning hypotheses into measurable quantities (Kim, 2014b). Studies start to arise that empower MOOC platforms to gauge the knowledge and competences of students and their capacity to learn (Fisher, Anderson, Peng, \& Leek, 2014).

Proliferation of technology. In the everyday life at a university, technology becomes more overt as well. After the computerization of the back end infrastructure and learning management systems like Moodle or Blackboard to streamline the communication between schools and students, the core activities of teachers and learners start to involve more technologies as well. Wikipedia has become an indispensable tool for students, and teachers already use E-textbooks and specialized apps like ExplainEverything! to create animations to explain certain concepts (Gonczarek \& Sliwinski, 2014). Universities start to use campus apps store with a collection of applications connected to the university and courses, possibly in combination with a smart educational dashboard on a tablet. For more information about educational technology, take note of the "Hype Cycle for Education," maintained by The University of Minnesota, that serves an overview of technologies, their current maturity and expected time frame for mainstream adoption (Hype Cycle for Education, 2014). Worries about privacy issues following the ever increasing tracking of students, evidence the same evolution (Caitlin, 201).

\section{Adaptive Learning and Creativity}

The commonly used behaviourist approaches are not particularly well suited to foster creativity and critical thinking. Yet, creativity-diminishing since the 1960s (Kyung, 2011)-is considered as the most crucial factor for future success and innovation, according to a survey of IBM ("IBM 2010," 2010). Though teamwork and collaboration can stimulate creativity (John-Steiner, 2006), more attention should be paid, for example, to using exploratory interactive learning environments.

A personal learning experience. One of the keys to improve online learning is to create a personal learning experience (Tokoro \& Steels, 2003), in which teaching is adapted to each student. The concept is often referred to as adaptive learning ("Google to Sponsor," 2014) and currently is barely 
present in MOOCs. Nevertheless, Benjamin Bloom observed that less instructional variation between students resulted in greater disparity in learning outcomes (Bloom, 1968). Providing a personal experience to a hundred thousand students with different learning goals and backgrounds is one of the future challenges (Lewin, 2013).

Gamification. A different approach to online learning is gamification. Teachers have been using games for years in their classes: a recent survey unveils that $74 \%$ of teachers in the USA use games and $73 \%$ of them use games at least once a week (Jhee, 2014). Gamification and serious games, the use of concepts and techniques from games outside the entertainment business, are being explored (Obama, 2011). One recent example is MineCraftEDU, reaching about 250,000 students (Waxman, 2012), where students can learn about history in a virtual world representing ancient societies, and where they can meet famous historical figures and embark on quests to learn about these fascinating cultures, explore genetics in real-time interactively (Kahn, 2013), simulate social conflicts, or get insight into the spread of epidemics through a simulator game (Brown, 2014).

\section{Conclusions}

The changing societal context has shaped new opportunities and expectations for education. To cope with the exploding demand for higher education, four universities with a capacity of 30,000 students each should be built, according to UNESCO (Stamenka, 2010). The generation of digital natives, in perfect comfort with new technologies like social media, mobile devices, cloud computing, and big data, find their style of living in deep conflict with the archaic prevalent way of teaching. And learners will become older and have different cultural backgrounds. Unfortunately, the lack of personalization and creativity turns too many students away from traditional learning environments.

The ultimate ambition of MOOCs is to bridge this gap and to provide cheap and democratic education to the masses. There are still some important barriers, however, towards this goal and the debate on MOOCs in the blogosphere and specialized press, centres around seven topics of discussion: (a) the high drop-out rate of students; (b) the business model of education (traditional and online); (c) the differences compared to face-to-face teaching; (d) the openness with respect reuse and redistribution; (e) the need for new pedagogies, metrics and methodologies, adapted to the massive scale; (f) whether MOOCs will lead to democratization or elitism; and ( $\mathrm{g}$ ) whether MOOCs mean the end of classical education.

Despite all the fuss, Massive Online Open Courses already seem to be changing the global landscape of education in important ways. This new evolution in computerized learning may have a significant organizational impact on institutions due to changed roles and economics of degrees, courses, and teaching:

- First, the role of teachers is slowly changing. Increasing research on how students to learn is fed back to teaching and the feedback process is closed by measuring the impact of teaching decisions on learning in MOOCs. It is already observed that the role of teachers evolves from transmission of knowledge to facilitating discussions and promoting non-cognitive and meta-cognitive skills (the flipped classroom). 
- We're heading towards a system of micro-credentials. The concept of the degree becomes slowly outdated as learning becomes more and more individual and competency-driven microcredentials. The core atomic learning object in MOOCs are courses, which are increasingly digitalborn. As students are no longer associated to a single degree or institution, the mobility of students and teachers is increasing, potentially leading to global communities of learners and teachers.

- A new discipline is emerging, coined Course Experience Design. Developing online courses are decisive in the success of learning, and is becoming increasingly complex. A shift towards team development and multi-disciplinary design (not unlike software development projects) is observed, involving field experts, instructional designers, data scientists, game designers, researchers, and programmers.

- Boundaries are blurring. A striking consequence of MOOCs is the fading of established boundaries on many different plans. The distinction between formal and informal learning, between public and for-profit education, and between teachers and learners is slowly fading. Also, the bounds of teaching are evolving: educational games, videos, and exercises are part of teaching in a distance learning setting.

- A revival of computers for learning is arriving. The omnipresence of advancement of information technology, in particular due to the Web, seems to have created a new momentum for online learning. Digitalization of education and using ICT to support it, continues, moving from the domain of virtual learning environments like Moodle, to the domain of learning, creating new research fields like educational data mining. Also, the use of technology is further progressing, evidence by e-textbooks, campus apps stores an education tablets. Lastly, the massive scale of MOOCs have urged the need for adaptive personalized learning experiences. Intelligent tutoring systems and gamification may provide the missing link.

MOOCs offer huge opportunities to reshape the educational industry, but these are not for free. Producing a high-quality digital-born course requires a multi-disciplinary team and a lot of planning. However, once constructed, its reach is much higher than traditional lecture-based teaching and the danger of disruptive innovation lurks. A lot of disciplines (maths, history, languages etc.) appeal to millions of learners worldwide and a more intensive reuse of educational resources is desirable. The global debate on education unleashed by MOOCs and the corresponding atmosphere of innovation and experimentation should be welcomed and may provide the necessary momentum to finally push online and digital learning over the tipping point.

\section{References}

Abrami, P.C., Bernard, R., Wade, A., Schmid, R. F., Borokhovski, E., Tamin, R., ... Peretiatkowicz, A. (2006). A review of e-learning in Canada: A rough sketch of the evidence, gaps and promising 
directions. Canadian Journal of Learning and Technology/La revue canadienne de l'apprentissage et de la technologie, 32(3). Retrieved from http://www.cjlt.ca/index.php/cjlt/article/view/27.

ACE Alternative Credit Project to Increase Attainment Levels for Nontraditional Learners with Some College, No Degree. (2014, September 10). Retrieved from http://www.acenet.edu/newsroom/Pages/ACE-Alternative-Credit-Project-to-Increase-Attainment-Levels-for-NontraditionalLearners-With-Some-College-No-Degree.aspx.

Alcorn, B., Christensen, G., \& Emanel, E. (2014, August 13). The real value of online education [Blog post]. Retrieved from http://www.theatlantic.com/magazine/archive/2014/o9/the-real-value-ofonlineeducation/375561/.

Allen, E., \& Seaman J. (2013, January). Changing course [Blog post], Babson survey research group and quahog research group. Retrieved from http://www.onlinelearningsurvey.com/reports/changingcourse.pdf.

Allen, E., \& Seaman, J. (2014, January). Grade change [Technical Report]. Newburyport, Massachusetts: Sloan Consortium. Retrieved from http://www.onlinelearningsurvey.com/reports/gradechange.pdf.

Aoun, J.E., Bustamante, B., Cowen, S. S., Crow, M. M., Ebersole, J. F., Khator, R. , ... Thor, L. M. (2013). Beyond the inflection point: Reimagining business models for higher education [Tech. Rep.]. American Council on Education. Retrieved from http://www.acenet.edu/newsroom/Documents/Beyond-the-Inflection-Point-Reimagining-Business-Models-for-HigherEducation.pdf.

Arizona State University. (2014, June 15). Starbucks, ASU team up for employee education program [News article]. Retrieved from https://asunews.asu.edu/20140615-starbucks-asu-partnership.

Arnett, T. (2014, January 6). Why disruptive innovation matters to education [Blog post] . Retrieved from http://www.christenseninstitute.org/why-disruptive-innovation-matters-toeducation/.

Bady, A. (2013, May 15). The MOOC moment and the end of reform [News article]. Retrieved from http://thenewinquiry.com/blogs/zunguzungu/the-mooc-moment-and-theend-of-reform/.

Baer, J. (2003). Grouping and achievement in cooperative learning. College Teaching, 51(4), 169-175.

Baker, D. (2014, November 19). Tech city UK launches free digital business academy [Blog post]. Retrieved from http://techcitynews.com/2014/11/19/tech-city-uk-digitalbusiness-academy/.

Bates, T. (2012, August 5). What's right and what's wrong about Coursera-style MOOCs [Blog post]. Retrieved from http://www.tonybates.ca/2012/08/05/whats-right-and-whats-wrongaboutcoursera-style-moocs/. 
Ben-Naim, D. (2014, August 21). The MOOC completion conundrum: Can 'born digital' fix online education? [Blog post] Retrieved from http://innovationinsights.wired.com/insights/2014/o8/mooc-completionconundrum-can-borndigital-fix-online-education/.

Bernhard, M., \& Rothberg, M. (2014, September 26). Amidst competition, HarvardX turns to new marketing strategies [article]. Retrieved from http://www.thecrimson.com/article/2014/9/26/HarvardX-new-marketing-MOOCS/.

Bloom, B.S. (1968). Learning for mastery. Evaluation Comment, 1(2), 1-11. Retrieved from http://programs.honolulu.hawaii.edu/intranet/sites/programs.honolulu.hawaii.edu.intranet/file s/upstfstudent-success-bloom-1968.pdf.

Borden, J. (2014, August 26). MOOCs are dead - Long live the MOOC [Article]. Wired Magazine. Retrieved from http://www.wired.com/2014/08/moocs-are-dead-long-live-the-mooc/.

Brindaalakshmi, K. (2014, August 23). Indian govt launches open repository for school education [Article]. http://www.medianama.com/2013/08/223-indian-govtlaunches-open-repository-forschool-education/.

Brooks, D. (2012, May 3). The campus tsunami [Article]. The New York Times. Retrieved from http://www.nytimes.com/2012/05/04/opinion/brooks-the-campustsunami.html? $\mathrm{R}=0$

Brown, A. (2014, September 24). Moocdemic starts spreading [Article]. Examiner. Retrieved from http://www.examiner.com/article/moocdemic-starts-spreading-september-29th.

Bruff, D. (2014, August 28). MOOC-Supported Learning Communities for FutureSTEM Faculty [Blog post]. Retrieved from http://derekbruff.org/?p=2938.

Button, K. (2014, November 18). U of OK for-credit courses offered as MOOCs [Article]. Retrieved from http://www.educationdive.com/news/u-of-ok-for-credit-coursesoffered-as-moocs/334229/.

Caitlin, E. (2014, November 29). Online education run amok? [Article]. Retrieved from http://www.politico.com/story/2014/11/online-education-run-amok-113208.htm

Cannell, P. (2014, December 3). Digital learning revolution underway [Blog post]. Retrieved from http://www.scotsman.com/news/digital-learning-revolution-underway-1-3617060.

Carmichael, R. (2014, November 18). 'Ivory Tower' explores higher education crisis on CNN [Blog post]. Retrieved from http://clatl.com/freshloaf/archives/2014/11/18/ivory-towerexplores-highereducation-crisis-on-cnn.

Carnoy, M. (1974). Education as cultural imperialism. New York, NY: McKay.

Chafkin, M. (2013, 12). Udacity's Sebastian Thurn, Godfather of free online education, changes course 


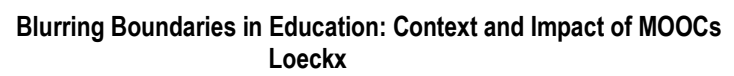

[Blog post]. Retrieved from http://www.fastcompany.com/3021473/udacity-sebastian-thrunuphill-climb.

Chattopadhyay, S. (2014, October 20). MOOCs: Forging diversity and innovation [Article]. Retrieved from http://www.business-standard.com/article/management/moocs-forgingdiversity-andinnovation-114101900686 1.html.

Christensen, C. M. (2013). The Innovator's Dilemma. Brighton, MA: Harvard Business Publishing.

Creative Destruction. (2014, June 28th). London, UK: The Economist. Retrieved from http://www.economist.com/news/leaders/21605906-cost-crisis-changing-labour-markets-andnew-technology-will-turn-old-institution-its.

Cuban, L. \& Cuban, L. (2009). Oversold and underused: Computers in the classroom. Cambridge, MA: Harvard University Press.

Davidson, C. N. and Goldberg, D. T. (2009). The future of learning institutions in a digital age. Cambridge, MA: MIT Press.

Designing the future(s) of the University. (2014). Retrieved from https://futures.georgetown.edu/.

Dodd, T. (2014b, October 6). Top MOOC provider edX no longer free for all [article]. Financial Review. http://www.afr.com/p/national/education/top mooc provider edx no longer FooMSmV3Ld SQHYGKND4LoI.

Duneier, M. (2012, September 3). Teaching to the world from central New Jersey [News article]. The Chronicle of Higher Education. Retrieved from http://chronicle.com/article/Teaching-totheWorld-From/134068/.

EdCast. (2014). Retrieved from http://www.edcast.com/corp/about us.

Educational Data Mining. (2014). Retrieved from http://en.wikipedia.org/wiki/Educational data mining.

Fisher, A., Anderson, G. B., Peng, R. \& Leek, J. (2014, October 16). A randomized trial in a massive online open course shows people don't know what a statistically significant relationship looks like, but they can learn [article]. PeerJ . Retrieved from https://peerj.com/articles/589/.

Five Habits of Highly Creative Teachers [web page]. (2014). Retrieved from https://www.canvas.net/courses/five-habits-of-highly-creative-teachers.

Foucault, M. (1980). Power/knowledge: Selected interviews and other writings, 1972-1977. New York, NY: Random House LLC.

Friday, L. (2014, October 29). MOOC explores alien worlds [news article]. Retrieved from http://www.bu.edu/today/2014/mooc-explores-alien-worlds/. 
Friedman, T L. (2013, January 26). Revolution hits the universities [news article]. New York Times. Retrieved from http://www.nytimes.com/2013/01/27/opinion/sunday/friedmanrevolution-hitsthe-universities.html.

Gartner Identifies the Top 10 Strategic Technology Trends for 2015 [article]. (2015, October 8). Retrieved from http://www.gartner.com/newsroom/id/2867917

Online Master of Science in Computer Science. (2014), Georgia Tech, College of Computing. Retrieved from http://www.omscs.gatech.edu/

Global key trends 2020 [report]. (2015). Retrieved from http://globalinfluences.com/social/communication-nation/technology-trends-2020/

Godin, S. (2012). Stop Stealing Dreams: (What is School For?). Retrieved from http://www.sethgodin.com/sg/docs/stopstealingdreamsscreen.pdf

Gonczarek, B., \& Sliwinski, P. (2014). Explain Everything Collaborative Whiteboard [website].Retrieved from http://www.morriscooke.com/?p=134.

Google To Sponsor MOOC Research. (2014, August). Retrieved from http://www.cmu.edu/homepage/computing/2014/summer/google-to-sponsormoocresearch.shtml.

Goul, M. (2013, July 20). What lurks beneath the tip of the MOOC iceberg? [Blog post] Retrieved from http://knowwpcarey.com/article.cfm?aid=1425.

Grainger, B. (2013). Massive open online course (mooc) report [Tech. Rep.]. University of London.

Guo, P. J and Kim, J., \& Rubin, R. (2014). How video production affects student engagement: An empirical study of MOOC videos [article]. In Proceedings of the first ACM conference on Learning@ scale conference, Atlanta, USA, p.41-50.

Haber, J. (2014a, October 1). My Harvard Embed [Blog post]. Inside Higher Ed. Retrieved from https://www.insidehighered.com/blogs/higher-ed-beta/my-harvard-embed.

Haber, J. (2014b, November 13). Some thoughts on a snapshot of conventional wisdom [Blog post]. Inside Higher Ed. Retrieved from https://www.insidehighered.com/blogs/higher-edbeta/somethoughts-snapshot-conventional-wisdom.

Haber, J. (2014c, September 2014). MOOCs. Cambridge, MA: MIT Press.

Habib, A., \& Woods, C. (2014, September 19). MOOCs - Panacea or benevolent curse? [Blog post] University World News. Retrieved from http://www.universityworldnews.com/article.php?story=20140916135824683.

Haggard, S. (2013). The maturing of the MOOC [Research paper]. Department for Business Innovation \& 
Skills, 1 Victoria Street, London SW1H oET, Retrieved from

https://www.gov.uk/government/uploads/system/uploads/attachment data/file/240193/131173-maturing-of-the-mooc.pdf

Hamilton, R. (2014, October 17). Universities rethinking their use of massive online courses [News article]. The New York Times. Retrieved from http://www.nytimes.com/2014/10/17/us/universities-rethinking-their-use-ofmassive-onlinecourses.html.

Hanban. (2014, August 14). Chinese courses available on MOOC platforms [News article]. Retrieved from http://english.hanban.org/article/2014-08/14/content 547884.htm.

Hattie, J. (2013). Visible learning: A synthesis of over 800 meta-analyses relating to achievement. New York, NY: Routledge.

Hepler, L. (2013, November 29). Can online education grow up? [Blog post] Retrieved from http://www.bizjournals.com/sanjose/print-edition/2013/11/29/can-onlineeducation-growup.html.

Hollands, F. M., \& Tirthali, D. (2014, May). MOOCs: Expectations and reality [Tech. Rep.]. Center for Benefit-Cost Studies of Education, Teachers College, Columbia University. Retrieved from http://www.academicpartnerships.com/sites/default/files/MOOCs Expectations and Reality.p df.

Holoiday, L. (2014, October 14). Edmonton youth design online coding course for latest University of Alberta MOOC [News article]. Metro news. Retrieved from http://metronews.ca/news/edmonton/1183150/edmonton-youth-design-onlinecoding-coursefor-latest-university-of-alberta-mooc/.

Hype Cycle for Education. (2014). Retrieved from https://hypecycle.umn.edu/.

IBM 2010 Global CEO Study: Creativity Selected as Most Crucial Factor for Future Success [Report] (2010, May 18). Retrieved from http://www-03.ibm.com/press/us/en/pressrelease/31670.wss.

Jenkins, H. P. I. (2009). Confronting the challenges of participatory culture [report]. Cambridge, Massachusetts: MIT Press. Retrieved from https://mitpress.mit.edu/sites/default/files/titles/free download/9780262513623 Confronting the Challenges.pdf.

Jhee, C. (2014, June 9). Digital games in the classroom: A national survey [blog post]. Retrieved from http://www.joanganzcooneycenter.org/2014/06/o9/digital-games-in-theclassroom-a-nationalsurvey/. 
John-Steiner, V. (2006). Creative collaboration. Oxford, UK: Oxford University Press. Retrieved from http://books.google.be/books?id=KQnPZ2fIUkUC.

Johnson, M. E. (2014, August 29). Flip your classroom and your attitude [News article]. Retrieved from http://www.pbs.org/mediashift/2014/o8/flip-your-classroom-and-your-attitude/.

Josh B. (2014, February 4). Spending on corporate training soars: Employee capabilities now a priority [Blog post]. Forbes. Retrieved from http://www.forbes.com/sites/joshbersin/2014/02/04/therecovery-arrivescorporate-training-spend-skyrockets/.

Kahn, B. (2013, April 8). Genetics in minecraft: Wool, mendel and brownies [Blog post]. Retrieved from http://www.middleschoolminecraft.com/2013/04/o8/genetics-in-minecraftwool-mendel-andbrownies/.

Kay, J., Reimann, P., Diebold, E., \& Kummerfeld, B. (2013). MOOCs: So many learners, so much potential [article]. IEEE Intelligent Systems, 3, 70-77.

Kim, J. (2014a, January 23). 6 big takeaways from the EdX global forum [Blog post]. Inside Higher Ed. Retrieved from https://www.insidehighered.com/blogs/technology-and-learning/6bigtakeaways-edx-global-forum.

Kim, J. (2014b, August 17). Here come the data scientists [Blog post]. Inside Higher Ed. Retrieved from https://www.insidehighered.com/blogs/technology-and-learning/here-comedata-scientists.

Kizilcec, R., Piech, C., \& Schneider, E. (2013). Deconstructing disengagement: Analyzing learner subpopulations in massive open online courses [article]. In Proceedings of the Third International Conference on Learning Analytics and Knowledge (pp.170-179), Leuven, Belgium.

Knox, J., Bayne, S., MacLeod, H., Ross, J., \& Sinclair, C. (2012, August 8). MOOC pedagogy: The challenges of developing for Coursera [Blog post]. Retrieved from https://newsletter.alt.ac.uk/2012/08/mooc-pedagogy-the-challengesof-developing-forcoursera/.

Koller, D. (2012). What we're learning from online education [presentation]. TED Talk, Retrieved https://www.ted.com/talks/daphne_koller_what_we_re learning from online education?lang $\underline{\text { uage }=n l}$

KVAB: Final conference on blended learning [website]. (2014, November 19). Retrieved from http://www.kvab.be/denkersprogramma/conference-blended-learning.aspx

Kyung H. K. (2011). The creativity crisis: The decrease in creative thinking scores on the torrance tests of creative thinking [article]. Creativity Research Journal, 23(4), 285-295. Abingdon, UK: Taylor \& Francis. Retrieved from http://dx.doi.org/10.1080/10400419.2011.627805. 
Lapowsky, I. (2014, September 26). Why free online classes are still the future of education [article]. Wired. Retrieved from http://www.wired.com/2014/og/free-online-classes-stillfutureeducation/.

Laurillard, D. (2002). Rethinking teaching for the knowledge society [report]. EDUCAUSE Review, 37(1), $16-24$.

Laurillard, D. (2014, January 16). Five myths about MOOCs [Blog post]. Times Higher Education. Retrieved from http://www.timeshighereducation.co.uk/comment/opinion/five-mythsaboutmoocs/2010480.article.

Levander, C. (2014, October 11). Levander: In Texas higher education, massive open online courses are money well-spent [Blog post]. Houston Chroniclee. Retrieved from http://www.houstonchronicle.com/opinion/outlook/article/Levander-In-Texas-highereducation-massive-open-5816611.php.

Lewin, T. (2012, July 29). Senate committee report on for-profit colleges condemns costs and practices [news article]. The New York Times. Retrieved from http://www.nytimes.com/2012/07/30/education/harkin-report-condemnsfor-profitcolleges.html.

Lewin, T. (2013, December 11). After setbacks, online courses are rethought [Blog post]. The New York Times. Retrieved from http://www.nytimes.com/2013/12/11/us/after-setbacks-onlinecoursesare-rethought.html? $\mathrm{R}=\mathbf{1}$.

Lewis, H. R. (2012, September). Reinventing the classroom [article]. Massachusetts, USA: Harvard Magazine. Retrieved from http://harvardmagazine.com/2012/og/reinventing-the-classroom.

Lipinski, J. (2014, 8 18). Tulane's “Trauma!” Course offers new approach to online learning [news article]. Retrieved from http://www.nola.com/education/index.ssf/2014/08/tulanes trauma offers new appr.html.

Liyanagunawardena, T. R., Adams, A. A., \& Williams, S. A. (2013). Moocs: A systematic study of the published literature 2008-2012 [article]. The International Review of Research in Open and Distributed Learning, 14(3), 202-227. Retrieved from http://www.irrodl.org/index.php/irrodl/article/view/1455/2531.

Lowendahl, J.-M. (2014). Your university of the future - Executing on the higher education business model scenarios [Tech. Rep.]. Gartner. Retrieved from http://www.eunis.org/eunisrectors14/wpcontent/uploads/sites/5/2014/04/Lowendahl-Eunisrectors-conference-Official.pdf.

Lynch, M. (2014a, October 13). CMU gets \$5 million grant to study learning [news article]. Retrieved from http://wesa.fm/post/cmu-gets-5-million-grant-study-learning. 
Manouselis, N., Drachsler, H., Verbert, K. \& Duval, E. (2013). Recommender systems for learning. New York, NY: Springer.

Marcus, J. (2014a, September 12). All hail MOOCs! Just don't ask if they actually work. Time. Retrieved from http://nation.time.com/2013/og/12/all-hail-moocs-justdont-ask-if-they-actually-work/.

Marcus, J. (2014b, January 21). Harvard, MIT: Despite low completion rates, MOOCs work [Blog post]. Hechinger Report. Retrieved from http://hechingerreport.org/content/harvard-mit-despitelowcompletion-rates-moocs-work-14495/.

Mazoué, J. G. (2014, November 10). Beyond the MOOC model: Changing educational paradigms [article]. Educause. Retrieved from http://www.educause.edu/ero/article/beyondmooc-model-changingeducational-paradigms.

Min-sik, Y. (2014, September 4). Online learning transforms education. Kore Herald. Retrieved from http://www.koreaherald.com/view.php\&ud=20140904001048.

MIT task force. (2014, July 28). "Institute-wide task force on the future of MIT education" [Tech.Rep.]. MIT. Retrieved from http://web.mit.edu/future-report/TaskForceFinal July28.pdf.

Moe, R. (2014, May 15). The MOOC problem. Retrieved from http://www.hybridpedagogy.com/journal/mooc-problem/.

Monter un MOOC de A à Z. (2014). Retrieved from https://www.france-universitenumeriquemooc.fr/courses/ENSCachan/20002S02/Trimestre 3 2014/about.

MOOCs Directory. (2014). Retrieved from http://moocs.co.

Moore, M. G., \& Kearsley, G. (1996). Distance education: A systems view. Belmont, CA: Wadsworth Publishing Company.

Morris, N. (2014, September 4). Don't dismiss MOOCs - we are just starting to understand their true value [Blog post]. The Conversation. Retrieved from http://theconversation.com/dont-dismissmoocswe-are-just-starting-to-understand-their-true-value-31037.

Murray, S. (2014, November 6). Distance learning: Internet opened "pandora's box" on education. Business Because. Retrieved from http://www.businessbecause.com/news/mbadistancelearning/2898/distance-learning-internet-opened-pandoras-box-on-education.

Myk, G., \& Rasmus, D. W. (2014). Invent the beyond. Retrieved from https://opencourses.desire2learn.com/cat/course/invent-the-beyond-7204/.

The Nexus of Forces: Social, mobile, cloud and information. (2014). Gartner. Retrieved from http://www.gartner.com/technology/research/nexus-of-forces/.

Ng, A. \& Koller, D. (2012). The online revolution: Education at scale [video]. Google Faculty Summit. 
Retrieved from https://www.youtube.com/watch?v=WdEeGmgRXiI

Nichols, V. (2014, November 5). Should you use MOOCs in learning? [Blog post] Retrieved from http://www.trainingzone.co.uk/feature/od/should-you-use-moocslearning/187882.

Obama, B. (2011). President Obama on Education at TechBoston [Video]. Retrieved from http://www.whitehouse.gov/photos-and-video/video/2011/03/o9/president-obama-educationtechboston\#transcript.

Online Evolution. (2014, September). Harvard Magazine. Retrieved from http://harvardmagazine.com/2014/og/online-evolution.

Open letter to professor Sandel. (2013, May 2). An Open Letter to Professor Michael Sandel from the Philosophy Department at San Jose State University [article]. In The Chronicle of Higher Education. Retrieved from http://chronicle.com/article/The-Document-Open-LetterFrom/138937/.

The Opportunities - and Risks -in the MOOC Business Model [article]. (2013, October 15). Retrieved from http://online.wsj.com/news/articles/SB10001424052702304561004579135363266072976.

O'Prey, P. (2013, May). Massive open online courses: Higher education's digital moment? [Tech. Rep.]. Universities $U \mathrm{~K}$.

Pappano, L. (2012). The year of the MOOC. The New York Times, 2(12).

Parry, M. (2013, September 3). A star MOOC professor defects - at least for now [Blog post]. The Chronicle of Higher Education. Retrieved from http://chronicle.com/article/A-MOOC-StarDefects-at-Least/141331/.

Paul, A. M. (2014, September 10). The MOOC gender gap. Retrieved from http://www.slate.com/articles/technology/future tense/2014/og/mooc gender gap how to $\mathrm{g}$ et more women into online

Petriglieri, G. (2013a, October 9). Education isn't just about churning out 'skilled' employees [Blog post]. Retrieved from http://blogs.wsj.com/experts/2013/10/og/education-isntjust-about-churningout-skilled-employees/.

Petriglieri, G. (2013b, October 9). Let them eat MOOCs [Blog post]. Retrieved from http://blogs.hbr.org/2013/10/let-them-eat-moocs/.

Public universities to raise own funds, says source. (2014, November 2). Retrieved from http://www.themalaymailonline.com/malaysia/article/public-universities-toraise-own-fundssays-source.

Rifkin, J. (2014). The zero marginal cost society: The internet of things, the collaborative commons, and 
the eclipse of capitalism. London, UK: Macmillan.

Rivard, R. (2013, August 1). MOOC bill dead for now [Blog post]. Inside Higher Ed. Retrieved from https://www.insidehighered.com/news/2013/08/01/controversial-californiabill-outsourcestudent-learning-dead-until-2014-or-later.

Romero, C., \& Ventura, S. (2010). Educational data mining: A review of the state of the art. Systems, Man, and Cybernetics, Part C: Applications and Reviews, IEEE Transactions on, 4O(6), 601618.

Sadler, P. M., \& Good, E. (2006). The impact of self-and peer-grading on student learning. Educational Assessment, 11(1), 1-31. Abingdon, UK: Taylor \& Francis.

Salem, M. (2014, August 14). New answer for the "free" education debate? [News article] Retrieved from http://www.al-fanarmedia.org/2014/o8/new-answer-free-education-debate/.

Sharples, M., Adams, A., Ferguson, R., Gaved, M., McAndrew P., Rienties B., \& Whitelock (2014). Innovating Pedagogy 2014: Open University Innovation Report 3 [Tech. Rep.]. The Open University.

Stamenka U.-T. (2010). Highlights [Presentation]. Retrieved http://www.unesco.org/new/fileadmin/MULTIMEDIA/HQ/ED/pdf/RANKINGS/StamenkaJohnDaniel.pdf

Stevens, B., Miller, R., \& Michalski, W. (2000). The creative society of the 21st century. In Vol. 1, chap. Social Diversity and the Creative Society of the 21st Century. OECD.

Tamburri, R. (2014, October 8). Universities experiment with their own MOOCs [Blog post]. Retrieved from http://www.universityaffairs.ca/universities-experiment-withtheir-own-mooc.aspx.

Terwiesch, C. \& Ulrich, K. (2014, November 16). Business schools must decide response to the digital revolution. Financial Times. Retrieved from http://www.ft.com/intl/cms/s/2/896bf6da-3f4111e4-984b-00144feabdco.html\#axzz3JW86zhR1.

Tokoro, M. \& Steels, L. (2003). The future of learning: Issues and prospects. Amsterdam, NL: IOS Press.

Tozzi, C. (2014, August 14). IBM, linux foundation, universities partner on open source mainframe computing [Blog post]. Retrieved from http://thevarguy.com/servers/o81414/ibmlinuxfoundation-and-universities-partner-open-source-mainframe-computing.

Trowsdale, D. (2014). Innovation: The key to business success [web site]. Retrieved from https://www.futurelearn.com/courses/innovation-the-key-to-business-success.

Vaughan-Nichols, S. (2014, October 7). Linux foundation certifications are taking off. Retrieved from http://www.zdnet.com/linux-foundation-certifications-are-taking-off-7000034431/. 
Waxman, O. B. (2012, September 21). MinecraftEdu teaches students through virtual world-building [Blog post]. Retrieved from http://techland.time.com/2012/09/21/minecrafteduteachesstudents-through-virtual-world-building/.

Webley, K. (2012, November 19). MOOC brigade: Can online courses keep students from cheating? Time. Retrieved from http://nation.time.com/2012/11/19/mooc-brigadecan-online-courses-keepstudents-from-cheating/

Westervelt, E. (2013, December 31). The online education revolution drifts off course. Retrieved from http://www.npr.org/2013/12/31/258420151/the-online-educationrevolution-drifts-off-course.

Wiley, D. (2014, September 18). The MOOC misstep and the open education infrastructure [Blog post]. Retrieved from http://opencontent.org/blog/archives/3557.

Wood, G. (2014, August 13). The future of college. Retrieved from http://www.theatlantic.com/features/archive/2014/o8/the-futureofcollege $/ 375071 /$ ?utm source=pocket\&utm medium=email\&utm campaign=pockethits

Woolf, B. P. (2009). Building intelligent interactive tutors: student-centered strategies for revolutionizing e-learning. Berlington, USA: Morgan Kaufmann Publishers.

Yuan, L. and Powell, S (2013). Moocs and open education: Implications for higher education. Lancaster, UK: Cetis. Retrieved from http://publications.cetis.org.uk/wpcontent/uploads/2013/03/MOOCs-and-Open-Education.pdf

\section{Athabasca} University 